\title{
AVERSÃO SEXUAL SOB UMA PERSPECTIVA FREUDIANA
}

\author{
Antonios Terzis ${ }^{1}$ \\ Gustavo Presídio de Oliveira ${ }^{2}$
}

Resumo: A aversão não adquiriu um estatuto de conceito na obra de Freud, porém abriga nela a série de afetos e reações, tais como o nojo e a repugnância, tendo grande importância na constituição e na vida do homem civilizado, assim como participa nas manifestações da repulsa à sexualidade e aos seus objetos. A aversão não é dada de antemão, mas é uma conseqüência da vida em cultura, constituindo o estágio inicial, após o complexo de castração, em que se erguem as barreiras à sexualidade infantil perversa e polimorfa em direção às aquisições culturais via o recalcamento, a sublimação, a identificação, etc. Trata-se do sinal afetivo-corporal em que a sexualidade perversa polimorfa se negativa na latência para dar vez a uma entrada subjetiva no âmbito social e cultural.

Palavras-chave: psicanálise, sexualidade infantil, aversão, desamparo.

Sexual aversion under a Freudian perspective (Abstract): Aversion is not properly a Freudian concept but it comprises a number of affects and reactions, such as disgust and repugnance, which play a capital role in the subjective constitution of the civilized man. It also takes part in the repulsive reactions to sexual acts and objects as expressed in various forms. Aversion is not given as a natural trait but is culture dependent, constituting the initial stage, post castration complex, where barriers emerge against the perverse polymorphic infantile sexuality leading to cultural acquisitions through repression, sublimation, identification, etc. Aversion is an affective-bodily latency signal where the infantile sexuality is negated to open the way to subjective entrance of the young into the social and cultural life.

Keywords: psychoanalysis, infantile sexuality, aversion, helplessness.

\footnotetext{
${ }^{1}$ PUC-Campinas, Brasil, www.cefas.com.br.

2 PUC-Campinas, Brasil, gugapre@hotmail.com

PSICOLOGIA, Vol. XXIII (1), 2009, Edições Colibri, Lisboa, pp. 149-163
} 
Nos textos de Freud os termos aversão e aversão sexual não são freqüentes sendo, portanto, desprovidos de estatuto conceitual, embora o primeiro possa ser encontrado esporadicamente nas cartas enviadas a Fliess, Carta 75 (1897/1996), e nas obras Estudos sobre a histeria (1893-1895/1996), Um caso de histeria (1905/1996) e, também, em Três ensaios sobre a teoria da sexualidade (1905/1996). Nelas, a palavra aversão parece ganhar significado semelhante a outras, como repugnância, nojo e asco.

A aversão, portanto, estaria significando algo repulsivo ao sujeito, de tamanha intensidade e força em relação a uma representação. No caso Dora (1905/1996), Freud se refere à aversão ao nomear a repugnância que sua paciente sentia em certas situações de assédio de cunho sexual e amoroso por parte do Sr. K., como se as excitações suscitadas na jovem moça fossem ainda mergulhadas no sangue representativo da realização do incesto, provocando a defesa aversiva no plano da oralidade da sexualidade infantil, esta que culmina, em sua trajetória, no drama edípico. A idéia aqui, na histeria, é a impossibilidade de atravessar a trama edípica. Diante dela, a libido recua para postos anteriores de sua trajetória, em que deixou, como diz Freud, uma parte de suas tropas. Porém, estas serão marcadas, retroativamente, em função do recalcamento oriundo da proibição do incesto, por uma defesa, no plano corporal afetivo (sem deixar de incluir, de uma forma velada, a realização alucinatória do incesto sob uma modalidade oral, em que se realiza o gozo histérico), invertendo os afetos - de um bom gosto para o nojo e a ojeriza. Assim sendo, a libido fica estancada no ponto de sua elaboração simbólica, e isto a partir do período da latência, no qual são erigidas, em função do Édipo, as barreiras em prol da inserção da criança no mundo social e cultural.

A passagem acima contém, de forma condensada, uma série de pressupostos da teoria freudiana relativos ao desenvolvimento sexual e à constituição de sujeito. A título de esclarecimento inicial, diremos que a sexualidade perversa polimorfa, incitada pelo adulto durante os cuidados vitais prestados à criança, é de natureza parcial, sendo que os objetos servem de apoio para uma satisfação inadiável pelas pulsões parciais, ativadas (pelo contato com o adulto) em toda a superfície do corpo e na atividade muscular. Esse caráter ilimitado e inadiável de satisfação e posse, que não é modulado por nenhum princípio da realidade, notório pelo respeito da espera diante da falta que o caracteriza, torna a sexualidade perversa polimorfa infantil incompatível com a realidade, com a vivência em sociedade. Uma lei com seus limites deve ser imposta, supondo a aquisição progressiva interna dessa lei e restrição para a inserção na cultura.

No início, é o ambiente do mundo adulto que garante o privilégio de um desfrute onipotente dessa sexualidade. Porém, com as frustrações necessárias do desmame e do controle dos esfíncteres, assim como de movimen- 
tos e restrições de posse, a criança terá uma tolerância relativa dessas imposições frustradoras em função da garantia amorosa, narcisista, de propiciar esse terreno da satisfação infantil; do contrário, a criança ficará sujeita ao horror da volta ao desamparo originário, da intrusão dolorosa e de abandono. Porém, é somente com uma separação do objeto, que se esboça com o primado do investimento no falo e a configuração da cena edípica, que todas as limitações anteriores vão ser, em um longo processo, subjetivadas sob a lei da proibição do incesto, quando ocorre o recalcamento da sexualidade infantil, a aceitação da castração e o caminho em direção à sexualidade adulta.

O início dessa empreitada é marcado pelo eclipse da sexualidade perversa polimorfa, a entrada em latência, quando barreiras internas são erigidas contra tal sexualidade, atestando-se na inversão de afetos; ou seja, o que dava outrora prazer imediato é objeto de aversão, para ser recalcado, simbolizado e transformado em empreendimento de laços sociais em torno da lei comum a todos. A "não aceitação" da castração na neurose barra o processo de simbolização, deixando o sujeito estancando nas próprias barreiras da lei, o que é atestado pela inversão dos afetos, que indica o recalcamento do desejo incestuoso, mas sem o desprendimento do mesmo.

Para elucidar essa trama, vamos iniciar com um breve resumo do desenvolvimento da libido que desemboca na latência para fornecer as bases do entendimento da aversão.

Breve explanação sobre os estágios de desenvolvimento psicossexual

No livro Três ensaios sobre a teoria da sexualidade (1905/1996), Freud postulou a existência da sexualidade infantil, bem como ampliou o conceito do sexual para além do órgão genital.

Poucos dos achados da psicanálise tiveram tanta contestação universal ou despertaram tamanha explosão de indignação como a afirmativa de que a função sexual se inicia no começo da vida e revela sua presença por importantes indícios mesmo na infância. E, contudo, nenhum outro achado da análise pode ser demonstrado de maneira tão fácil e completa (FREUD, 1925 [1924]/1996, p. 39).

A indignação ressaltada no trecho acima faz pensar como, há séculos, e na sua própria investigação, a sexualidade suscita algo de tão recalcado, incômodo e agressivo. Em uma conferência que comemorava o aniversário de Freud no Centro Anna Freud em 27 de abril de 1995 (apud Rev. Psicanálise e Universidade, 2003, p. 12), Green discutia a importância da sexualidade para a psicanálise e alertava para o descaso que tem recebido no seio da psicanálise atual, quando escutou de um psicanalista: "vocês franceses são freudianos demais, e, além disso, vocês se atêm muito ao pênis". Green 
respondeu: "velha objeção: Freud, segundo seus detratores, era um obcecado sexual; se somos freudianos demais, este é, portanto, igualmente nosso caso"'. A sexualidade ainda é, então, um forte alvo de repulsa, de aversão.

Freud (1905/1996) mostrou a existência e a vivência da sexualidade na criança, através de estágios do desenvolvimento sexual. Estimulada pelo adulto, em meio à provisão das necessidades vitais, a criança busca a cada momento e em cada região do corpo a descarga e a obtenção de alívio e prazer.

Assim, como consta em nota de Abraham (1970, p. 52), "a expressão sexual não é um fenômeno independente, mas depende de uma função importante para a preservação da vida, a saber, o ato de sugar em busca de nutrição, de maneira que é a reprodução de um estímulo agradável que a criança experimentou durante a alimentação". Nesse momento, predominantemente oral, mamar no seio é a fonte estimuladora da pulsão sexual.

O segundo estágio da organização da libido é a analidade. Nela, a criança obtém satisfação ao evacuar ou reter as fezes no intestino. Essa atividade favorece o relacionamento com o mundo, não só pela absorção, como também pela expulsão de conteúdos, através de suas fezes, entendidas, no âmbito narcísico e com a configuração da separação do outro, como sendo presentes para o adulto ou usadas para agredi-lo.

No estágio fálico, a criança tenderá a exacerbar determinado valor ao órgão genital masculino, já que nessa fase não existe uma diferenciação entre masculino e feminino; o que é preponderante na concepção do infante é ter um pênis ou não tê-lo, uma vez que este constitui fonte principal do prazer e gozo. Desta maneira, já se pode inferir que existe a substituição do conjugado ativo - passivo (encontrado na fase anal-sádica) para quem possui falo ou quem é castrado. Os genitais são excitados e estimulados pela masturbação, atividade que é favorecida por conta da "posição anatômica, pelas secreções em que estão banhadas, pela lavagem e fricção advindas dos cuidados com o corpo e por certas excitações acidentais (como as migrações de vermes intestinais)" (Freud, 1905/1996, p. 177).

\section{Dinamismo da libido e suas fontes de excitação}

A descrição sumária acima, porém, necessita de melhor contextualização para compreendermos o que segue: vimos que a sexualidade infantil polimorfa é provocada pelo adulto em meio aos cuidados que este presta ao

\footnotetext{
${ }^{3}$ Esse trecho de um artigo de Green mostra como a sexualidade ainda gera, em muitos, psicanalistas ou não, certo desdém e certa depreciação, nas raízes dos quais se encontra o recalcamento e sua acoplada aversão à sexualidade infantil.
} 
bebê. Essa erotização, que abrange toda a superfície do corpo, tem, no entanto, um destacado roteiro desde a oralidade até o investimento fálico, com as distintas modalidades de cada região corporal e estágio. As manifestações sensoriais e musculares crescentes da descarga e de busca de prazer da sexualidade infantil revelam, porém, uma atividade auto-erótica, como se reiterando, em loco, as excitações se desdobrando sobre si, que outrora foram incitadas pelo adulto. Aparentemente mecânica, essa passagem, em que nasce a manifestação propriamente pulsional, condensa importantes transformações.

É instrutivo que a criança, sob a influência da sedução, possa tornar-se perversa polimorfa e ser induzida a todas as transgressões possíveis. Isso mostra que traz em sua disposição a aptidão para elas; por isso sua execução encontra pouca resistência, já que, conforme a idade da criança, os diques anímicos contra os excessos sexuais - a vergonha, o asco e a moral - ainda não foram erigidos ou estão em processo de construção (FREUD, 1905/1996, p. 180).

Assim, nos estágios primários da vida, o bebê não tem noção de seu corpo, de estar separado do ambiente; todas suas atividades se dão no terreno narcísico primário. Porém, em certo momento, afirma Freud, o bebê nota que o seio ao qual se endereçava buscando alimento e alívio pertence a um corpo separado, dando-se conta, concomitantemente, da existência-separação do seu corpo. Nesse instante, "a pulsão se torna auto-erótica" (para essa descrição cf. Freud, início do V capítulo do terceiro ensaio de 1905); ou seja, as propriedades de prazer próprio e a noção do próprio corpo começam a se esboçar na mente do bebê.

$\mathrm{O}$ auto, esse recuo para si, significa, entre outros aspectos, o nascimento das fantasias, como sementes do mundo psíquico da criança que acompanham as atividades sexuais infantis. Embora Freud não precisasse o momento, ele coincide com a configuração do narcisismo secundário, concomitantemente à entrada no Édipo (perto de 2 anos de idade), como se a reunião em torno do falo na primeira configuração da trama edípica esboçasse junto a ela o corpo separado do ambiente: uma transposição transitiva da libido, do falo sobre o corpo e do corpo sobre o falo (cf. Freud, 1914/1996, a respeito do investimento narcísico do falo).

Freud nos coloca, nesse instante, uma série de questões que podemos apenas mencionar. Em primeiro lugar, é preciso entender que a sexualidade perversa polimorfa ocorre num terreno do narcisismo primário, ou seja, onde há uma indistinção ou pouquíssima distinção entre si e o mundo (Freud afirma que o eu da criança nesse estágio é indiferente em relação ao mundo 1915/1996). É apenas com o avanço da libido em direção ao falo que reporta ao narcisismo secundário, ou seja, que incide com a distinção eu-outro. Trata-se de uma afirmação problemática, já que Freud jamais a 
afirma com essa contundência, embora esta possa ser inferida em seus estudos. Perguntamos, então, como ocorre esse direcionamento ao falo e à cena edípica?

Trata-se de uma convergência de duas fontes, uma apoiada na outra: de um lado o ambiente é estruturado pela lógica edípica (por exemplo, pensamos nos significantes menino e menina com os quais se reporta o ambiente junto à criança); porém, ela encontra uma sustentação filogenética, por esquemas já propostas no sujeito, das fantasias originárias que articulam o Édipo. De outro lado, a experiência viva lida com a processual necessidade da separação dos corpos, ou seja, da aquisição da noção de estar separado. As fantasias originárias permitem que, nessa trajetória, advenha, com a construção das zonas erógenas, o mundo das fantasias e das teorias sexuais infantis que articulam a elaboração da sexualidade infantil em torno do Édipo. Lembramos que as fantasias originárias lidam com a origem da sexualidade (sedução), da geração (cena primária) e dos sexos (castração), as três se remetendo uma à outra e articulando a trama de Édipo, além de uma quarta fantasia, acrescida mais tarde por Freud, focada no retorno ao seio materno.

As teorias sexuais infantis se reportam, também, ao questionamento das origens; porém, em sua revelação positiva, compartilham com as fantasias filogenéticas uma atenção à cena primária (via de regra agressiva em relação à mãe), além de erigir uma teoria sobre a ubiqüidade do pênis nos seres do mundo (em paralelo com a fantasia filogenética de castração), mas se voltam primordialmente sobre a origem dos bebês, que faz paralelo com a do retorno ao seio materno das fantasias filogenéticas. As teorias sexuais infantis nascem com a entrada na fase edípica, quando notamos o início sob a constituição edípica do narcisismo, ou seja, da separação do ambiente, pela regressão defensiva, em que o questionamento de onde vem os bebês é atribuído, conforme "a concentração de tropas" da libido, a um dos estágios desta: concepção, nascimento ou devoração dos bebês na e pela boca, ou concepção, nascimento e destruição dos bebês na e pela cloaca, etc.

Vejamos, pois, que o ambiente e a filogenia propõem os significantes, as rotas e o programa edípico para a libido, cuja significação e finalidade, pela castração, é a constituição de um sujeito separado. As teorias infantis atestam, claramente, como indicamos acima, da perlaboração dessa separação, dentro da trama edípica, em que se luta contra o viés narcisista que resiste ao luto implícito e à separação do objeto primário, luto inerente à aceitação da castração para a entrada em cultura. A perlaboração carrega consigo essa transposição retroativa e defensiva, ou seja, em meio ao refúgio narcísico da castração e da libido sobre os estágios da libido, oral e anal. Estes adquirem uma configuração fantasmática (da problemática edípica), 
ou seja, de significantes culturais, porém sob o modo narcísico (ubiqüidade do pênis, concepção, nascimento e bebês).

Queremos assinalar com isso algo que Freud sempre frisou e que diz respeito ao tempo psíquico, como tempo misturado entre uma re-significação, après-coup, e uma determinação vetorial do tempo: um recuo diante da proibição do incesto, retomando as tropas deixadas para trás no caminho da libido ou dificuldade de reconhecer plenamente essa proibição (como na perversão e na psicose), já que traumas precoces geram fixações significativas nos estágios primários da libido. Estes articulam a possibilidade no vai e vem da re-significação, fantasmática em direção à aquisição simbólica da castração, ou, respectivamente, a uma verdadeira atuação fantasmática nos estágios regressivos da libido.

\section{Aversão sexual na constituição psíquica}

Os parágrafos anteriores versavam sobre a estratégia e a lógica do desenvolvimento da libido que culmina com o Édipo e a castração. Entretanto, precisamos voltar aos aspectos corporais e afetivos dessa perlaboração, que diz respeito à economia afetiva do recalcamento em que se implica a aversão na constituição psíquica.

$\mathrm{Na}$ fase fálica existe uma construção imaginária da teoria infantil, já mencionada, de que todas as pessoas possuem um pênis, sendo que, posteriormente, os infantes descobrem (pela manipulação genital e no prazer deste ato) que existem pessoas com falo e outras não. Essa diferenciação fará com que seja dada maior e mais intensa valorização a esse objeto. $\mathrm{Na}$ manipulação masturbatória, a criança acaba por conceber uma atenção, que antes não era dada com tanta veemência, aos seus próprios órgãos genitais. Porém, essa atenção não se restringirá apenas ao seu corpo e, servindo-se da pulsão escopofílica, ela também será atraída a observar os órgãos genitais das outras pessoas, sejam estas pai, mãe, irmãos, coleguinhas, de animais e até mesmo os seres inanimados. Importante ressaltar que, antes disso, o menino não faz nessa fase uma distinção entre os sexos e nem mesmo diferencia os órgãos das outras pessoas do dele. Ou seja, para ele "é natural presumir que todos os outros seres vivos, humanos e animais, possuem um órgão genital como o seu próprio".

A criança adentra a trama edípica que abriga o conflito incestuoso do complexo de Édipo e a decorrente angústia de castração. A mãe e, possivelmente, a irmã podem se tornar, então, alvos desejados pela criança do sexo masculino, havendo a necessidade preponderante de se interromper as investidas ao objeto desejado incestuoso, para que o indivíduo se torne sujeito de seus próprios desejos e agente na construção e manutenção da cultura, pertinentes para o bem-estar da sociedade. 
A angústia de ser castrado recai no menino a partir do momento em que este recebe as ameaças externas. Freud (1933[1932]/1996, p. 90) ressalta que a castração não pode ser entendida como uma ação real de retirar o pênis do menino, ou como uma ação resultante do fato de ele ter se apaixonado pela genitora; ao contrário, na angústia de castração "o que é decisivo é que o perigo ameaça de fora e a criança acredita nele". Essas ameaças geralmente advêm das pessoas que, ao brincarem com a criança, dizem que vão cortar o pênis dela, da própria mãe que tenta punir seu filho por estar manipulando o pênis, e também do fato de a criança se masturbar ou até mesmo quando tem enurese noturna. A aversão sexual da mãe ante a masturbação do infante possui, porém, uma importante e necessária função para a separação simbólica entre ambos, contribuindo na instauração do complexo de castração 4 .

A fantasia de castração ocorre prioritariamente quando a criança se sente ameaçada em perder seu pênis (Freud, 1924/1996, p. 195). No entanto, outras experiências anteriores a esse período tornam-se preparatórias para o momento do complexo edípico, como: "a retirada do seio materno a princípio de modo intermitente, e mais tarde, definitivamente - e a exigência cotidiana que lhes é feita para soltarem os conteúdos do intestino". Para sermos mais precisos, esses "cortes" são re-significados a posteriori à luz da ameaça de castração na fase fálica. A angústia de castração, ao ser vivenciada pela criança, fará com que, conseqüentemente, ocorra a dissolução do complexo edípico, quando o menino deixará de investir sua libido no objeto incestuoso desejado, por conta do "temor da castração — isto é, pelo interesse narcísico nos órgãos genitais", e tenderá a sublimar seus impulsos sexuais para atividades sociais.

Nesse período, também, ao defrontar-se com a ausência do pênis nas meninas, os meninos terão a fantasia de que elas fizeram algo de errado e, por isso, foram punidas com a castração. Mediante isso, eles tendem a desprezá-las e se comportam como se fossem superiores a elas.

Contudo, esses comportamentos e as experiências dessa fase podem trazer conseqüências futuras para alguns homens, como o aparecimento de sintomas neuróticos na vida adulta, caracterizados pela aversão à ausência do pênis nas mulheres, além do desprezo pelo fato de elas não o possuírem, o que ocorre com alguns homossexuais.

\footnotetext{
${ }^{4}$ Não somente a repreensão da mãe às atividades da masturbação do seu fillho caracteriza-se como uma aversão à sexualidade, contribuindo na instauração do complexo de castração. Existe, na fase anal, uma aversão dos cuidadores às atividades executadas pela criança, em pegar, cheirar as fezes, comer, reter e expulsar, entre outros. Neste momento surgem as primeiras e mais explícitas repulsas.
} 
No Complexo de Édipo feminino, a menina manipulará seu clitóris, extraindo prazer dessa atividade. No entanto, da mesma maneira que o menino, tenderá a observar se outros seres vivos ou inanimados possuem o mesmo órgão que o dela, e se extraem, da mesma maneira, prazeres ao manipulá-lo. Ao deparar-se com o fato de o menino possuir um órgão genital maior e diferente do seu, tenderá a hesitar e relutar contra essa descoberta. Desta atitude, segundo Freud (1931/1996, p. 241), "aferra-se obstinadamente à expectativa de que um dia também terá um órgão genital do mesmo tipo, e seu desejo por ele sobrevive até muito tempo após sua esperança ter-se expirado". Inicialmente, a menina aceita essa castração como uma punição de algo que desejou, porém, mais adiante perceberá que outras pessoas não possuem o pênis, como a sua própria mãe, sofrendo uma desilusão que a leva a culpar sua genitora por não ter lhe dado um pênis. É nesse período que o complexo de Édipo feminino comporta-se com um caráter masculino; e somente com o decorrer do tempo, torna-se feminino.

Ao se descontentar por ter nascido sem pênis, a menina se afastará de sua mãe e buscará uma aproximação com seu pai, a fim de possuir um substituto do pênis que não teve, por meio de um filho gerado com esse pai. Vale ressaltar que este seria um caminho para a dissolução satisfatória de seu complexo de Édipo, no qual se constitui a feminilidade. Contudo, existe a possibilidade de, insatisfeita com o seu órgão genital, a menina ser aversiva à masturbação e/ou ao interesse sexual em geral, ou mesmo de manter o desejo de possuir um pênis no futuro e, com isso, buscar se auto-afirmar na masculinidade por longo período. Assim sendo, para Freud, esta última escolha pode levar a uma orientação homossexual na fase adulta.

A fase de latência surge após a saída da criança do complexo edípico; ou seja, o sujeito entra em latência em função da necessidade de recalcar a sexualidade infantil quando esta desemboca nos desejos incestuosos, decorrentes do investimento narcísico do falo, que compreende o último estágio da trajetória da libido.

A latência, esse caldeirão efervescente em que se constitui o sujeito, é o período mais relevante para nosso estudo. $\mathrm{O}$ crepúsculo da atividade perversa polimorfa ocorre porque essa espécie paradisíaca narcísica da infância deve ser abdicada em função da realidade da castração. A criança se vê obrigada a abrir mão do amor dos pais, buscando seu lugar entre outros sujeitos. A sexualidade infantil passa por uma transformação sublimatória radical: a bissexualidade é sublimada para que possa servir aos laços sociais, submetendo-se às leis sociais que passam a ser internalizados em um supereu. As pulsões sofrem inibições dos fins a serviço das moções afetivas, sendo que a sublimação das pulsões se coloca a serviço das funções simbólicas do pensamento, da racionalização e dos encargos do traba- 
lho no âmbito das instituições propostas pela sociedade (escola, tarefas grupais ordenadas no campo da arte e do esporte, etc.).

Segundo Freud (1917[1916]/1996, p. 330), a partir do quinto ano de vida até aproximadamente o oitavo, a criança passa por uma etapa do seu desenvolvimento psicossexual em que, a priori, haverá uma calmaria em suas moções sexuais: "podemos observar uma parada e um retrocesso no desenvolvimento sexual, que, nos casos em que culturalmente há mais condições, podemos chamar de período de latência".

É essa etapa que torna o desenvolvimento sexual bi-temporal relevante, por favorecer o homem a investir na cultura e no convívio social, sendo, porém, um fator preponderante para "tendência à neurose".

A instauração bi-temporal do desenvolvimento sexual nos seres humanos, ou seja, sua interrupção pelo período de latência, pareceu-nos digna de uma atenção especial. Ela se figura como uma das condições da aptidão do homem para o desenvolvimento de uma cultura superior, mas também de sua tendência à neurose. Ao que saibamos, nada de análogo é demonstrável entre os parentes animais do homem. A origem dessa peculiaridade humana deveria ser buscada na proto-história da espécie (FREUD, 1905/1996, p. 220).

Para Freud (1923/1996, p. 58), nesse período, as pulsões sexuais submetem-se a uma orientação negativa de sua costumeira descarga, dando vez a destinos diversos. Uma pressão defensiva, diante da proibição do incesto e do correlato horror de castração, faz desviar essas moções sexuais de seus fins. Os elementos representativos sendo recalcados, seus correspondentes afetivos acabam sendo invertidos: em vez de expectativa e descarga prazerosa, há um repúdio, vergonha, asco e ojeriza. Uma grande parte da energia sexual é "dessexualizada e sublimada (coisa que provavelmente acontece com toda transformação que resulta em uma identificação) e é, em parte, inibida em seus fins e transformada em impulsos de afeição". Vejamos que, em vez da descarga (em direção ao objeto), há uma volta sobre si (negativação) necessária para a identificação, utilizada para a aquisição de laços e sentimentos sociais, sublimando as correntes bissexuais da sexualidade infantil. Essa mesma contenção de descarga promove, em vez de descarga, uma inibição dos fins, reforçando os laços ternos das correntes afetivas do amor primitivo primário.

Assistimos, pois, às aparições dos comportamentos aversivos à sexualidade infantil, edificando-se e se tornando, ao mesmo tempo, bastante claras aos olhos do observador. A diferenciação dos sexos, implícita à castração, assim como o incesto implícito à relação corporal entre sexos opostos, gera uma aversão à sexualidade genital heterossexual (e de seus precursores pré-genitais polimorfos), ao mesmo tempo em que se reforçam os laços grupais e a valorização de bens culturais, da higiene e do julgamento 
moral: é quando vemos os grupos, meninos de um lado, meninas de outro, sendo que em cada um viceja os laços da homossexualidade sublimada e a formação social. A aversão é, então, inerente à entrada na cultura e na vivência em sociedade; porém, cede aos poucos com a estabilização, pela aquisição sublimatória, no interior do sujeito do código e valores sociais.

Então, "tem-se a impressão de que a construção desses diques é obra da educação e, certamente, a educação tem muito a ver com isso" (FREUD, 1905/1996, p. 167); contudo, esta apenas fornece o conteúdo, direcionando-o para um processo cujo projeto, timing e realização são determinados pela filogenia, ou melhor, na interlocução desta com a trama singular do Édipo de certo sujeito cuja articulação e a configuração inicial, como mostramos acima, nos é denotada no trabalho das teorias sexuais infantis.

O recalcamento impõe a amnésia infantil, a qual Freud (1905/1996, p. 164) explicita como sendo um esquecimento parcial ou total das lembranças vivenciadas pelo infante na primeira eflorescência da sua sexualidade. Assim, o recalcamento atuaria como sendo um bloqueio dessas vivências, que, "na maioria das pessoas (mas não em todas!), encobre os primeiros anos da infância, até os seis ou oito anos de idade". Serão reprimidas e apagadas pela consciência as experiências sexuais dos estágios oral, anal e a masturbação fálica, tais como o brincar com as fezes, ou seja, o prazer de sentir o cheiro ou a consistência dos excrementos, de retê-las ou expelir com força; a satisfação de chupar, morder o seio materno; colocar tudo que é objeto na boca; de friccionar o pênis e/ou clitóris e todas as fantasias sexuais desse período.

O recalque instaurado com maior intensidade na dissolução do Complexo de Édipo fará com que o pré-púbere recalque as representações e as pulsões sexuais vivenciadas nos estágios anteriores. No entanto, surgirão na consciência pensamentos opostos aos encontrados no inconsciente. A formação reativa surgirá como barreira, mecanismo que auxilia o recalcamento nos seus fins, fazendo com que as atitudes ou os costumes exercidos pelo sujeito sejam opostos aos desejos recalcados no inconsciente: "a esse processo chamo reforço reativo e designo por pensamento reativo o pensamento que se afirma na consciência com hiper-intensidade e que, a maneira de preconceito, mostra-se indestrutível" (Freud, 1905/1996, p. 60). Portanto, observa-se na latência um comportamento característico de aversão às atividades perversas polimorfas das experiências sexuais infantis. $\mathrm{O}$ ascetismo e a intelectualização são dois estados que serão mais valorizados pelos pré-púberes durante esse período.

Em suas atividades rotineiras, esses aspirantes jovens acabam temendo a quantidade de suas pulsões em vez da qualidade; ou seja, o excesso é prestes a evocar a rememoração e o atiçamento da sexualidade infantil e suas pulsões parciais, as quais foram reprimidas nesta etapa de sua vida. 
Contrariar qualquer tipo de anseio tornar-se-á a maneira mais correta de renunciar às avalanches pulsionais, que tanto amedrontam, pelo poder de as possuírem. Para o eu, a saída encontrada é vetá-las com o maior rigor. A aversão sexual encontra-se em ação nessas interações temerosas, com maior notoriedade e limpidez.

Conforme Anna Freud (2006), quando não compensada, a política de contrariar os desejos mais urgentes (o que pode ser compreendido, em nosso estudo, como aversão sexual) poderá generalizar-se e tornar-se perigosa.

Podemos compreender que existe uma conexão entre a abstenção de bonitas e atraentes roupas e a proibição de sexualidade. Começamos, porém, a ficar inquietos quando essa renúncia se estende a coisas que são inofensivas e necessárias, como no caso de um jovem que recusa qualquer proteção contra o frio, mortificando o corpo de todos os modos possíveis e expondo sua saúde a riscos desnecessários; quando não só renuncia a determinadas espécies de prazer oral, mas, "em princípio”, reduz sua alimentação diária ao mínimo; quando, pelo fato de ter gozado de longas noites de profundo sono, se obriga a estar de pé muito cedo; quando é relutante ao riso ou ao sorriso; ou quando, em casos extremos, retém a defecação e a micção o maior tempo possível, baseando-se em que não deve ceder imediatamente a todas as necessidades fisicas (Anna Freud, 2006, p. 111).

Para Freud (1924/1996), o equilíbrio conquistado pelo eu durante a latência, a despeito das investidas pulsionais do isso, ensaia uma possível desestruturação, em decorrência da entrada do sujeito na maturidade, em que se implicam alterações nas condições fisiológicas, dos pulsos sexuais secundários (em relação à eflorescência libidinal infantil). Neste sentido, tais condições favorecerão estimulações pulsionais, as quais são transportadas para a esfera psíquica, na forma de um influxo de libido.

A saída da fase de latência e a entrada na puberdade serão marcadas por muito conflito psíquico, pelo fato de o eu não conseguir, na maioria das vezes, estabelecer a mesma ordem e equilíbrio presenciados na fase de latência. Segundo Anna Freud (2006, p. 104), na adolescência “'os interesses orais e anais há muito submersos voltam à superfície. Os hábitos de limpeza, laboriosamente adquiridos durante o período de latência, cedem seu lugar ao prazer na imundície e na desordem".

Na puberdade, os impulsos e as relações de objeto dos primeiros anos de uma criança se tornam reanimados e entre eles os laços emocionais do seu complexo de Édipo. Na vida sexual da puberdade, verifica-se uma luta entre os anseios dos primeiros anos e as inibições do período de latência (FREUD, 1926 [1925]/1996, p. 42).

Essa re-ascensão, desta vez bastante violenta, do conflito edípico e seus precursores infantis sexuais marcam uma segunda elaboração da trama 
edípica para o processo com uma finalidade diferente da etapa inicial (entre 2 e 5 anos), pois, desta vez há necessidade e condição para uma abdicação definitiva (com seus possíveis fracassos) dos objetos incestuosos em prol do encontro com o "objeto externo" (Feud, 1905/1996). Novamente, a consideração do tempo de elaboração psíquica obrigará, na incitação secundária da libido, o tratamento regressivo dos resquícios não dissolvidos do complexo de castração infantil que carregam consigo seus precursores de origem da sexualidade perversa polimorfa. Aqui são passíveis de serem evocados, e de forma mais violenta e penosa, os diques da aversão sexual e suas ambigüidades, tais como encontramos na histeria, o que levou Freud (1895/1996) a afirmar que toda adolescência é impregnada de uma histeria. Nesse abalo sofrido pelo eu, as moções sexuais tendem a voltar à consciência, e o mecanismo do recalque torna-se menos rígido, em comparação àquele presente na fase de latência. As formações reativas que apoiavam o recalque perdem sua força. Fantasias do Complexo de Édipo surgem e tendem a vir à consciência de maneira deformada - nos meninos, cada vez mais com representações da castração, e nas meninas, da inveja do pênis.

Para Anna Freud (2006, p. 104), "há muito poucos elementos novos nas forças invasoras. Sua investida apenas traz outra vez à superfície o conteúdo familiar da sexualidade infantil nas crianças de tenra idade". De fato, esses comportamentos denunciam que o complexo edípico não se dissolveu como era esperado após o recalque e o complexo de castração. A aversão sexual se instaura nesse momento, o que fomenta contra as recorrentes investidas do conflito incestuoso e agressivo da sexualidade infantil.

As exigências do isso em expressar suas pulsões e, em contrapartida, as exigências do supereu, através da consciência moral, das formações de ideais e obediência da lei, fazem com que o eu procure restaurar a normalidade experimentada anteriormente na latência. Neste caso, o eu usará de todos os mecanismos de defesa que possam conter tanto essas investidas pulsionais do isso como as reaquisições do supereu. Para Freud (1924/1996, p. 205), após sofrer uma frustração no período do complexo edípico, o eu púbere poderá ceder às exigências do supereu e inibir as investidas do isso, gerando uma neurose de transferência. Ou, também, ceder às requisições do isso e "se afastar de um fragmento da realidade", podendo desenvolver uma psicose. No caso da neurose narcísica, na melancolia, o eu entraria em conflito com o supereu.

A partir da dissolução do Complexo de Édipo iniciada na esteira da latência, bem como o direcionamento do eu, na sua negociação entre o isso, o supereu e o mundo externo, consolidam-se as estruturas psíquicas. É em meio às suas formações que se coloca a aversão sexual. Sendo assim, na neurose de transferência, a aversão pode ser observada nos sintomas histéricos conversivos, nos pensamentos obsessivos ou mesmo nas fobias a 
ambientes ou a objetos, os quais podem representar alguma repugnância sexual recalcada. Já os delírios persecutórios e paranóicos da psicose são as expressões da aversão sexual existente no sujeito, sendo a sujeira, no delírio, infligida ou atribuída ao sujeito, como se fosse advindo de fora - do outro. No que se refere à perversão, a aversão pode ser encontrada nos rituais fetichistas, no nojo expressado pelos homossexuais com relação ao órgão genital do sexo oposto, entre outros.

\section{Considerações}

Portanto, buscamos precisar aqui o significado atribuído por Freud ao sentimento de aversão. E também esclarecer que aversão, para o autor, tem a mesma conotação que repugnância, afastamento horrorizado da sexualidade, nojo e repulsa a qualquer objeto, fantasia e a situações que pudessem vir a denotar algum aspecto da sexualidade perversa polimorfa. A aversão sexual, deste modo, é uma via contrária à sexualidade infantil até a matriz incestuosa que se instaura somente com a configuração edípica e a ameaça de castração, como parte do recalcamento das moções incestuosas e como parte do complexo conjunto de processos que permitem a entrada do sujeito na cultura. Entretanto, a aversão deve, com essa transformação, dar lugar à simbolização, à sublimação e à criação de laços sociais. Sua permanência alude para o estancamento de tal processo.

\section{Referências}

Abraham, K. (1970). Teoria psicanalítica da libido: sobre o caráter e o desenvolvimento da libido. Rio de Janeiro: Imago.

Freud, A. (2006). O ego e os mecanismos de defesa. Porto Alegre: Artmed.

Freud, S. (1924). A dissolução do Complexo de Édipo. In Edição standard brasileira das obras completas de Sigmund Freud (E.S.B.). v. XIX. Rio de Janeiro: Imago, 1996.

Freud, S. (1923). A organização genital infantil: uma interpolação na teoria da sexualidade. In Edição standard brasileira das obras completas de Sigmund Freud (E.S.B.). v. XIX. Rio de Janeiro: Imago, 1996.

Freud, S. (1897). Carta 75. In Edição standard brasileira das obras completas de Sigmund Freud (E.S.B.). v. I. Rio de Janeiro: Imago, 1996.

Freud, S. (1933 [1932]). Novas conferências introdutórias sobre psicanálise. In Edição standard brasileira das obras completas de Sigmund Freud (E.S.B.). v. XXII. Rio de Janeiro: Imago, 1996. 
Freud, S. (1940 [1938]). Esboço de psicanálise. In Edição standard brasileira das obras completas de Sigmund Freud (E.S.B.). v. XXIII. Rio de Janeiro: Imago, 1996.

Freud, S. (1893-1895). Estudos sobre a histeria. In Edição standard brasileira das obras completas de Sigmund Freud (E.S.B.). v. II. Rio de Janeiro: Imago, 1996.

Freud, S. (1905 [1901]). Fragmento da análise de um caso de histeria. In Edição standard brasileira das obras completas de Sigmund Freud (E.S.B.). v. VII. Rio de Janeiro: Imago, 1996.

Freud, S. (1931). Sexualidade feminina. In Edição standard brasileira das obras completas de Sigmund Freud (E.S.B.). v. XXI. Rio de Janeiro: Imago, 1996.

Freud, S. (1914). Sobre o narcisismo: uma introdução. In Edição standard brasileira das obras completas de Sigmund Freud (E.S.B.). v. XIV. Rio de Janeiro: Imago, 1996.

Freud, S. (1905). Três ensaios sobre a sexualidade. In Edição standard brasileira das obras completas de Sigmund Freud (E.S.B.). v. VII. Rio de Janeiro: Imago, 1996.

Freud, S. (1925 [1924]). Um estudo autobiográfico. In Edição standard brasileira das obras completas de Sigmund Freud (E.S.B.). v. XX. Rio de Janeiro: Imago, 1996.

Freud, S. (1916-1917 [1915]). Conferências introdutórias sobre psicanálise. In Edição standard brasileira das obras completas de Sigmund Freud (E.S.B.). v. XV. Rio de Janeiro: Imago, 1996.

Green, A. (2003). A sexualidade tem alguma relação com a psicanálise. Rev. Psicanálise e Universidade, São Paulo, n. 18, pp. 11-32.

Kuhn, T. S. (1972). La structure des révolutions scientifiques. Paris: Flammarion. 